\title{
The Effect of Training Parents in Couples' Communication Model on Attention Deficit Hyperactivity Disorder Symptoms in 4-9 Year-Old Students in Isfahan
}

\author{
Arghavan Shariat (corresponding author) \\ Department of Educational Science and Psychology, \\ Isfahan University, Isfahan, Iran \\ Tel: 00989130112748 \\ E-mail: ashariat@rocketmail.com \\ Mokhtar Malekpour \\ Department of Educational Science and Psychology, \\ Isfahan University, Isfahan, Iran \\ E-mail: mokhtarmalekpour@ymail.com \\ Amir Ghamarani \\ Department of Educational Science and Psychology, \\ Isfahan University, Isfahan, Iran, \\ E-mail: a.ghamarani@edu.ui.ac.ir
}

Received: 25-08- 2013

doi:10.7575/aiac.ijels.v.1n.2p.34
Accepted: 01-10-2013

Published: $31-10-2013$

URL: http://dx.doi.org/10.7575/aiac.ijels.v.1n.2p.34

\begin{abstract}
Attention deficit hyperactivity disorder (ADHD) is one of the most common neuropsychological childhood disorders that causes inconvenience to children, families, and the society. The objective of the present research is to investigate the effect of teaching Couples' Communication Model on the symptoms of ADHD in 4-9 year-old students. For this purpose, 60 students suffering from attention deficit disorder/hyperactivity-impulsivity were selected using multi-stage cluster sampling method and randomly assigned into an experimental or a control group with equal proportion. The data were analyzed using inferential statistics method (Covariance analysis). The findings revealed that training parents in the Couples' Communication Model could significantly decrease the symptoms of ADHD in children $(\mathrm{P}<0.05)$. It is recommended that this method be used as a non-pharmacological method to treat ADHD in children.
\end{abstract}

Keywords: Couples' Communication Model, hyperactivity and attention deficit disorder, 4-9 year-old student.

\section{Introduction}

Attention deficit hyperactivity disorder (ADHD), sometimes referred to as attention deficit disorder (ADD) or hyperkinetic disorder (HKD), is a neurological disorder or, in more exact words, a biological-psychological and social disorder. ADHD is one of the most prevalent disorders in children and adolescents that includes symptoms such as restlessness, hyperactivity and lack of attention. These symptoms vary in different people, though (Barkley, Fischer, Smallish, \& Fletcher, 2002).

A neuropsychological disorder entails $70-80 \%$ genetic risks and may be influenced by environmental factors as well. Genetic predisposition of ADHD is complicatedly associated with environment(Bollaert, 2002). ADHD begins at early childhood and is diagnosed with increasing levels of abnormal overactivity, uncontrolled movement and disregarding behavior as well as mental disorders. ADHD is mainly developed as a result of cerebral chemical imbalance, which leads to insufficient attention, overactivity and precipitancy (Brookes et al., 2006; Faraone, Biederman, \& Mick, 2006).

It is not easy to diagnose ADHD as it is also related to other conditions such as learning disability, behavioral disorders, bipolar and maniac-depressive disorders (Bollaert, 2002). The number of children diagnosed with ADHD is continuously increasing. ADHD is currently recognized as the most prevalent neurological syndrome in schoolchildren in the U.S that afflicts 3 to 5 percent (2 million) of children (Fewell \& Deutscher, 2002). Paloyelis assert that the reports by US department of education have estimated 3-5 percent of schoolchildren (about 2 million) with ADHD(Paloyelis, Mehta, Kuntsi, \& Asherson, 2007). However It is estimated that 3-7 percent of school children suffer from 
ADHD(Barkley, 1997; Weinstein, 2004). Some ADHD symptoms include excessive attention to irrelevant stimuli and lack of attention to relevant stimuli. Attention deficit may prevent children from paying careful attention to relevant details or have them make mistakes in homework, assigned tasks or other activities.

As for the etiology of ADHD, one may refer to a variety of factors. First of all, a series of acquired biological factors should be considered, including the factors pertaining to fetal life, exposure to alcohol, nicotine, low birth weight and cerebral infections that cause Encephalitis or the swelling of the brain. Besides, although psychological factors such as family instability, parents' mental disorders, poor parenting skills and poor socio-economic status are not considered as the main factors inducing ADHD, they play an important role in the demonstration of ADHD symptoms and may intensify them(Mall, 2013). Since ADHD symptoms create problems in children's social and educational life and may cause troubles to the family and society at large, it is crucial to develop appropriate treatment procedures.

Considering the aforementioned discussion, the present study aims to investigate the effect of teaching Couples' Communication Model on the symptoms of ADHD in 4-9 year-old students.

\section{Materials and Method}

The present study adopts a quasi-experimental method. The population of the study consisted of 60 parents whose 4-9 year-old children were diagnosed with ADHD in Isfahan in 2013. The participants were selected based on multi-stage cluster random sampling using Child Symptom Inventory-4 (CSI-4). The participants were then randomly assigned into either a control or an experimental group, each with 30 members. The research was conducted under the supervision of the School of Psychology of Isfahan University. Before the study was started, all participants were informed of the research aims and objectives and also Informed parental consent (child consent where applicable) was obtained (Shariat, Tamrin, Danaee, \& Karimi, 2013).

The independent variable was training parents in Couples' Communication Model offered to the experimental parents. In order to select the participants, the educational districts of Isfahan city were considered first. Using multi-stage cluster sampling, two districts were randomly selected. Eventually, a number of 60 children with attention deficit/ hyperactivity-impulsivity symptoms were selected as the subjects of the study.

Following the completion of the questionnaires, 30 parents (experimental group) were trained in Couples' Communication Model in seven sessions, depending on the parents' level of participation. The control subjects received no intervention, though.

\subsection{Instrument}

CSI-4 is a common screening tool for psychiatric disorders, which is developed based on The Diagnostic and Statistical Manual of Mental Disorders (DSM). The first version of the scale was developed by Sprafkin and colleagues based on the third version of DSM, which was called Sprafkin- Loney- Yunithath- Gadow Inventory after its developers(Sprafkin, Volpe, Gadow, Nolan, \& Kelly, 2002). CSI-3R was developed in 1987. Eventually, CSI-4 was developed by Gadow and Sprafkin in 1994 based on the fourth version of DSM (DSM-IV). The last version of CSI-4 consists of two forms of parent and teacher checklists. The parent checklist was used in the present study. CSI-4 comprises 112 items eighteen items of which (Category A) address hyperactivity and attention deficit disorder. The items are on a 4-point Likert scale including Never, Sometimes, Often and Very Often. The questionnaire used in the present study consisted of 18 items (Category A) that examined three distinct subscales of attention deficit and hyperactivity including inattention disorder, dominant impulsivity hyperactivity and mixed-type hyperactivity. The dominant inattention subscale, dominant impulsivity hyperactivity subscale and the mixed-type hyperactivity subscale are addressed by items 1-9, 10-18 and 1-18, respectively. The scoring procedures for CSI-4 include Screening Cutoff Scoring and Symptom Severity Scoring. The scale has been used in many studies and examined in terms of its reliability, validity, sensitivity and characteristics. Grayson and Carlson reported that the sensitivity of CSI-3R for ADHD was 0.77(Gerdes, Haack, \& Schneider, 2012; Grayson \& Carlson, 1991). Other researchers, calculated the reliability of the scale using split-half method, which yielded a reliability index of 0.91 for teacher checklist and 0.85 for parent checklist(Miranda, Jarque, \& Remírez, 2006). The content validity of the CSI-4 questionnaire was approved by nine psychiatrists in a study(Johnston \& Mash, 2001). We used a translated version of CSI-4 questionnaire that was approved by Faculty of Psychology, Isfahan University, Iran.

\subsection{Statistical Analysis}

The effect of this education on parents was examined on the test scores of the experimental subjects and was subsequently compared with the test scores of control subjects.

The data was analyzed using SPSS software. Descriptive statistics including mean and standard deviation were used to describe the data. Inferential statistics including Covariance analysis were used to examine the between-group differences.

\section{Results}

Table 1 illustrates the mean scores and standard deviation of hyperactivity and its subscales both before and after the intervention. The results of Covariance analysis are also presented in the table to compare the mean scores of the control and experimental groups after the intervention. 
Table1. Mean scores and standard deviation of hyperactivity and its subscales before and after the intervention

\begin{tabular}{|c|c|c|c|c|c|c|c|}
\hline \multirow[t]{2}{*}{ Statistics } & \multirow[t]{2}{*}{ Step } & \multicolumn{2}{|c|}{ Experimental } & \multicolumn{2}{|c|}{ Control } & \multirow[t]{2}{*}{$\mathrm{F}$} & \multirow[t]{2}{*}{$\mathrm{P}$} \\
\hline & & Mean & SD & Mean & SD & & \\
\hline \multirow{2}{*}{$\begin{array}{l}\text { Dominant } \\
\text { inattention }\end{array}$} & Pretest & 22.83 & 7.26 & 22.86 & 5.88 & \multirow[t]{2}{*}{4.732} & \multirow[t]{2}{*}{0.041} \\
\hline & Posttest & 20.30 & 5.65 & 22.66 & 6.01 & & \\
\hline \multirow{2}{*}{$\begin{array}{l}\text { Dominant } \\
\text { impulsivity } \\
\text { hyperactivity }\end{array}$} & Pretest & 23.60 & 7.10 & 22.86 & 6.06 & \multirow[t]{2}{*}{8.367} & \multirow[t]{2}{*}{0.005} \\
\hline & Posttest & 21.50 & 5.36 & 22.20 & 6.71 & & \\
\hline \multirow{2}{*}{$\begin{array}{l}\text { Mixed-type } \\
\text { hyperactivity }\end{array}$} & Pretest & 46.43 & 13.14 & 45.73 & 10.38 & \multirow[t]{2}{*}{6.968} & \multirow[t]{2}{*}{0.011} \\
\hline & Posttest & 39.80 & 9.32 & 44.86 & 11.48 & & \\
\hline
\end{tabular}

As shown in Table 1, the posttest mean scores of the experimental group are smaller than posttest mean scores of the control group across the three subscales. This finding suggests that training parents in the Couples' Communication Model could reduce ADHD symptoms in 4-9 year-old children in dominant inattention subscale, dominant impulsivity hyperactivity subscale and the mixed-type hyperactivity subscale $(\mathrm{P}<0.05)$.

\section{Discussion and Conclusion}

The present study was conducted to investigate whether or not training parents in the Couples' Communication Model could reduce ADHD symptom in their children including inattention, hyperactivity and the type of impulsivity.

There have been numerous studies on the effect of parent training in ADHD symptoms on children. Research has shown that training and education may be one of the best ways to deal with this disorder. ADHD is one of the most prevalent biological-psychological and social disorders in children and adolescents that may affect different aspects of their life including emotional, social and educational domains. The present findings revealed that teaching Couples' Communication Model could significantly reduce ADHD symptoms in children including inattention, hyperactivity and impulsivity(Daly, Creed, Xanthopoulos, \& Brown, 2007).

It is reported that families gained significantly more knowledge about ADHD disorder following a training program. This suggests that parents' perceptions would change their attitudes so that they may attribute their children's behavior to ADHD. This would increase their cooperation to apply the behavioral principles they have learned in training sessions. Parents' increased knowledge may help decrease children's behavioral problems(Sadock, 2000).

In previous researches, it is reported that there may be a reciprocal, effective relation of parents and home environment with attention deficit and hyperactivity. Research has shown an association between the demonstration of ADHD symptoms and lack of family solidarity, family conflicts, divorce and psychiatric disorders. They reported parents' behavioral training significantly reduced attention deficit/hyperactivity symptoms in children. The participants reported that parents' behavioral training increased parents' self-confidence in dealing with their children, changed their attitudes, improved their interpersonal relationship with each other and with their children, reduced a sense of guilt and increased family mental health(Pavuluri, Luk, \& McGee, 1999).

Other research, reported that a combination of parent behavioral training and medication reduced hyperactivity symptoms in children with ADHD(Kalantari, Yule, \& Gardner, 1993). Anastopoulos reported improved parents' performance and decreased behavioral problems of ADHD children following nine training sessions and two months of follow-up (Anastopoulos, Shelton, DuPaul, \& Guevremont, 1993).

As a conclusion, our research showed the positive effect of Training Parents in Couples' Communication Modelon Attention Deficit Hyperactivity Disorder Symptoms in 4-9 Year-Old Students and it is suggested for the future research to do same protocol for bigger population with different categories of ages.

\section{Acknowledgement}

Thanks to Isfahan University Department of Educational Science and Psychology (Iran). We would like to express our special thanks to Mr. Ardalan Shariat for his guidance in spite of his very busy schedule. Last but not least, our many thanks go to the editorial board, Rachel Hua Yeh Fung who helped us a lot in finalizing this text within the limited time frame.

\section{References}

Anastopoulos, A. D., Shelton, T. L., DuPaul, G. J., \& Guevremont, D. C. (1993). Parent training for attention-deficit hyperactivity disorder: Its impact on parent functioning. Journal of abnormal child psychology, 21(5), 581-596.

Barkley, R. A. (1997). Behavioral inhibition, sustained attention, and executive functions: constructing a unifying theory of ADHD. Psychological bulletin, 121(1), 65. 
Barkley, R. A., Fischer, M., Smallish, L., \& Fletcher, K. (2002). The persistence of attention-deficit/hyperactivity disorder into young adulthood as a function of reporting source and definition of disorder. Journal of abnormal psychology, 111(2), 279.

Bollaert, R. (2002). Zit stil! op school!: omgaan met ADHD in de klas. Lannoo Uitgeverij.

Brookes, K.-J., Mill, J., Guindalini, C., Curran, S., Xu, X., Knight, J., ... Taylor, E. (2006). A common haplotype of the dopamine transporter gene associated with attention-deficit/hyperactivity disorder and interacting with maternal use of alcohol during pregnancy. Archives of General Psychiatry, 63(1), 74.

Daly, B. P., Creed, T., Xanthopoulos, M., \& Brown, R. T. (2007). Psychosocial treatments for children with attention deficit/hyperactivity disorder. Neuropsychology review, 17(1), 73-89.

Faraone, S. V, Biederman, J., \& Mick, E. (2006). The age-dependent decline of attention deficit hyperactivity disorder: a meta-analysis of follow-up studies. Psychological medicine, 36(2), 159-166.

Fewell, R. R., \& Deutscher, B. (2002). Attention deficit hyperactivity disorder in very young children: Early signs and interventions. Infants \& Young Children, 14(3), 24-32.

Gerdes, A. C., Haack, L. M., \& Schneider, B. W. (2012). Parental Functioning in Families of Children With ADHD Evidence for Behavioral Parent Training and Importance of Clinically Meaningful Change. Journal of attention disorders, 16(2), 147-156.

Grayson, P., \& Carlson, G. (1991). The Utility of a DSM-III-R-based Checklist in Screening Child Psychiatric Patients. Journal of the American Academy of Child \& Adolescent Psychiatry, 30(4), 669-673.

Johnston, C., \& Mash, E. J. (2001). Families of children with attention-deficit/hyperactivity disorder: review and recommendations for future research. Clinical Child and Family Psychology Review, 4(3), 183-207.

Kalantari, M., Yule, W., \& Gardner, F. (1993). Protective factors and behavioral adjustment in preschool children of Iranian martyrs. Journal of Child and Family Studies, 2(2), 97-108.

Mall, M. (2013). Looking at the impact of ADHD on children (833kb). British Journal of School Nursing, 8(1), 39.Miranda, A., Jarque, S., \& Remírez, J. F. R. (2006). Treatment of children with ADHD: Psychopedagogical program at school versus psychostimulant medication. Psicothema, 18(3), 335-341.

Paloyelis, Y., Mehta, M. A., Kuntsi, J., \& Asherson, P. (2007). Functional MRI in ADHD: a systematic literature review. Expert review of neurotherapeutics, 7(10), 1337-1356.

Pavuluri, M. N., Luk, S.-L., \& McGee, R. (1999). Parent reported preschool attention deficit hyperactivity: measurement and validity. European child \& adolescent psychiatry, 8(2), 126-133.

Sadock, B. J. (2000). Kaplan \& Sadock's Comprehensive Textbook of Psychiatry (2 Volume Set) (pp. 89-114). lippincott Williams \& wilkins.

Shariat, A., Tamrin, S. B. M., Danaee, M., \& Karimi, H. (2013). The responses of white blood cells to weight lossamong young male judoists. Russian Open Medical Journa, 2, 1-3.

Sprafkin, J., Volpe, R. J., Gadow, K. D., Nolan, E. E., \& Kelly, K. (2002). A< i $>$ DSM-IV $</$ i $>-$ Referenced Screening Instrument for Preschool Children: The Early Childhood Inventory-4. Journal of the American Academy of Child \& Adolescent Psychiatry, 41(5), 604-612.

Weinstein, D. F. (2004). Culture at work: Family therapy and the culture concept in post $\square$ World War II America. Journal of the History of the Behavioral Sciences, 40(1), 23-46. 